\title{
ACUTE HIV: WHAT IS NEW AND DO WE TREAT?
}

Health care providers are faced with a number of challenges with regard to acute HIV infection. The first of these is recognition, because the acute retroviral symptoms mimic a number of other viral infections. The second challenge is treatment, as treating early HIV has a number of benefits and risks both on an individual and a public health level. This review hopes to address some of these questions.

Although the HIV pandemic is not a new phenomenon, there are still significant gaps in knowledge that influence progress in prevention and treatment strategies. Most of these gaps involve the first few days and weeks of infection, i.e. the period of acute HIV infection.

Acute HIV infection (AHI) is usually defined as the time from entry of the virus into the body to completion of seroconversion, while early-stage HIV infection generally refers to the interval between seroconversion and the establishment of the viral load set point. The magnitude of the viral set point is prognostic for disease progression.

Tests such as rapid HIV tests are initially negative in acute HIV as there is a delayed immune response. Seroconversion can occur as late as 6 months after exposure, while detectable levels of viraemia and p24 antigenaemia develop over the first 3 - 4 weeks of infection. ${ }^{2,3}$

Evolution of symptoms of the acute retroviral syndrome usually coincides with high levels of viraemia and the host's initial immunological response. The classic mononucleosis-like symptoms of acute HIV-1 infection (fever, joint pain, inguinal lymphadenopathy and night sweats) may last several days to weeks and are found in at least $47 \%$ of patients with $\mathrm{AHI}^{4,5}$

Several studies suggest that individuals with acute HIV infection can be identified in sexually transmitted infection (STI) clinics and perhaps other high-risk settings.,

The detection of acute HIV infection is important not only from a research and prevention point of view but because it may also allow for early treatment that could modify the natural history of the disease. ${ }^{7}$

\section{METHODS}

MEDLINE and PubMed databases were searched using the keywords 'Acute HIV', 'natural history of HIV', 'HIV in Africa' and 'immunology of HIV'. More recent articles were focused on, i.e. those published after 2000.

\section{PUBLIC HEALTH ISSUES}

The diagnosis of acute HIV infection is important from a public health point of view. ${ }^{8}$ Patients are highly infectious and HIV transmission occurs readily owing to a massive viral burden in the blood and genital secretions. ${ }^{9}$ Acute HIV may therefore account for a disproportionate amount of HIV transmission. Patients may be unaware that they are infected and continue to engage in risky behaviour, putting others at risk. The differential d iagnosis of an unexplained viral syndrome in a sexually active adult should always include acute HIV. $^{10}$

A study in heterosexual couples in the Rakai district of Uganda showed an increased risk of HIV transmission in the period just following HIV acquisition. In 10 out of 23 initially uninfected couples both partners seroconverted within the same 10-month follow-up period. A 'per-act transmission rate' of 0.0082 was calculated for this 'early transmission' group by dividing the total number of transmission events by the total number of sex acts reported by the 23 couples. A much smaller transmission rate was obtained for couples who were serodiscordant at enrollment. ${ }^{11}$

Another study from Botswana showed that identification of acute HIV was possible in a public health setting. This was viewed as an important part of reducing the epidemic in this country in combination with early use of HAART, risk reduction counselling, partner notification and contact tracing. ${ }^{12}$

\section{NATURAL HISTORY OF AHI}

The natural history of HIV-1 has been well characterised in industrialised countries. A cohort study of homosexual men showed a steep decline in CD4+ Tcell counts after seroconversion. HIV RNA load at the

THE SOUTHERN AFRICAN JOURNAL OF HIV MEDICINE — JULY ZOOg 
first HIV-seropositive visit ( 3 months after seroconversion) was highly predictive of AIDS, with prognosis correlating with subsequent HIV RNA measurements. The CD4+ T-cell decline was generally more severe in patients with higher CD4+ T-cell count levels before infection, which may reflect greater HIV replication. ${ }^{1}$

A subgroup of patients from a Swiss and Australian cohort showed that both the incubation period of AHI (time between HIV infection and AHI) and duration of $\mathrm{AHI}$ were associated with the late prognosis of HIV infection. The incubation period of AHI was independently associated with progression towards AIDS. ${ }^{13}$

Information regarding the natural history of HIV-1 infection in Africa is limited. In a prospective cohort study of female sex workers in Mombasa, Kenya, the survival rate was similar to that for HIV-1-infected individuals in developed countries before the introduction of highly active antiretroviral therapy (HAART). This was supported by a review of African studies from Uganda and Malawi. A higher viral load set point and more severe acute HIV-1 illness predicted faster progression to death. Disease in an African cohort, however, did not progress faster to AIDS than an industrialised country cohort. $^{14,15}$

\section{PRESENTING SIGNS AND SYMPTOMS}

It is estimated that between $40 \%$ and $90 \%$ of patients with $\mathrm{AHI}$ experience an acute retroviral syndrome (ARS). Symptoms usually occur $2-6$ weeks after exposure to HIV-1 and typically last 14 days, but may persist for as long as 10 weeks. ${ }^{4}$

The significance of the severity of seroconversion symptoms is not known, but the presence of seroconversion symptoms has been correlated with more rapid disease progression. ${ }^{4,14}$

Common symptoms include fever ( $>80-90 \%)$, fatigue (>70 - 90\%), pharyngitis (50-70\%), weight loss, night sweats (50\%), lymphadenopathy (40 - 70\%), arthralgia or myalgia $(50-70 \%)$, headache $(32-70 \%)$, skin rash $(>40-80 \%)$, and nausea, vomiting and diarrhoea (30 - 60\%). The rash is typically maculopapular and usually involves the trunk. It may be difficult to detect in black African cohorts. Other less frequent symptoms include aseptic meningitis (24\%), oral ulcers (10 $20 \%$ ) and genital ulcers $(5-15 \%)$, while frequent nonspecific laboratory findings include leukopenia (40\%), thrombocytopenia (45\%) or mild transaminitis (21\%). ${ }^{16}$ Other unusual presentations include myopericarditis, acute renal failure, cranial nerve VII palsy, radiculopathy and opportunistic infections such as candidiasis, cytomegalovirus infection, and Pneumocystis jirovecii pneumonia. ${ }^{4}$
The nonspecific nature of acute retroviral symptoms and the extensive differential diagnosis often make the identification of this syndrome challenging. It is important to consider this diagnosis in order to obtain an appropriate history, perform an appropriate risk factor assessment, perform a thorough physical examination, and order appropriate diagnostic tests. ${ }^{4,17}$

\section{DIAGNOSIS OF AHI}

In an article by Fiscus et al., AHI was considered to be present if HIV RNA results were positive and one of the following conditions were met: (i) rapid antibody tests both negative; (ii) rapid antibody tests discordant and Western blot results negative or indeterminate; and (iii) rapid antibody tests discordant and Western blot results weakly positive with subsequent band evolution. $^{18}$

In contrast, Hoen et al. used three laboratory criteria to confirm the diagnosis of primary HIV infection: (i) positive p24 antigenaemia; (ii) negative HIV enzyme-linked immunosorbent assay (ELISA) or positive ELISA in a patient who could be confirmed HIV negative within the past 3 months; and (iii) $<3$ bands in the Western blot test. $^{19}$

The p24 band is usually the first to become positive in the Western blot test during seroconversion. If this is the only band present the HIV antibody test is considered to be indeterminate. This result should be correlated with the HIV-1 plasma RNA level. ${ }^{4}$

As CD4+ T-cell counts can briefly decrease during acute infection, they are generally not reliable markers of immune status during the first 6 months of infection. ${ }^{4}$

\section{TREATMENT}

The value of initiating antiretroviral therapy during $\mathrm{AHI}$ is uncertain. There are no randomised control trials examining the long-term effects of early treatment on the clinical course and prognosis of HIV infection. Results from studies are conflicting, and some evidence shows that early treatment may not alter the viral set point consistently following interruption., ${ }^{4,20}$

The benefits and risks of initiating therapy for AHI continue to be discussed. Potential benefits include the control of acute retroviral symptoms, prevention of abnormal helper T-cell function and reduction in the pace of decline, delaying or preventing decreased immune function and vulnerability to opportunistic infections, decreasing the initial viral load set point, which may decrease transmission, limiting viral evolution and diversity, potential slowing of the rate of disease progression among patients with a genetic predisposition, and decrease in the size of the latent HIV pool. ${ }^{4,20}$ 
Risks include increased cost, adverse effects and abnormal metabolic findings, drug resistance, long-term challenges to adherence, and unknown long-term toxicities or expected duration of benefit. ${ }^{4}$

A US study in 47 patients showed that initiation of HAART within 90 days of HIV-1 infection was associated with reduced HIV-1 virus levels, improved CD4+ T-cell counts and immune conservation, decreased opportunistic infections, and decreased frequency of respiratory and mucocutaneous conditions when used for 78 weeks. Rapid progression to AIDS also was avoided. However, side-effects of combination therapy were commonly reported in this study. ${ }^{21}$

\section{IMMUNOLOGICAL EFFECTS OF ART IN PATIENTS WITH AHI}

The limited benefit of antiretroviral therapy initiated during $\mathrm{AHI}$ may be explained to some degree by the early depletion of lymphocyte reservoirs in the gastrointestinal tract reported in some studies. This may also help to explain the conflicting evidence between early observations demonstrating apparent immunological benefit with early antiretroviral treatment with the inability to control viral replication after treatment interruption. $^{20}$

Only a few reports describe the effects of HAART on HIV-specific T-cell responses during acute HIV infection. ${ }^{22,23}$ However, limitations such as small sample size, short duration of follow-up and lack of concomitant virological data need to be taken into account when interpreting these results. ${ }^{23}$ In a cohort of 16 HIV-1infected individuals who received their diagnosis at the time of seroconversion and who were started on HAART within 72 hours, a robust HIV-1-specific CD4+ T-cell proliferative response was observed and viraemia was contained. ${ }^{22}$

One prospective cohort study followed up participants from the time of acute infection and examined different virological profiles related to various treatment interventions. No correlation was observed between baseline viral load and HIV-specific CD4+ and CD8+ T-cell responses. Subjects who started HAART at the time of acute infection had no better HIV-specific Tcell responses than those who started therapy after seroconversion, and the absence of any treatment or the incomplete virological control did not prevent the development of an HIV-specific CD4+ T-cell response. This may imply that early therapy aimed at preserving the HIV-specific immune response may not be necessary in all subjects. ${ }^{23}$

\section{WHEN TO START TREATMENT}

The period during which treatment for acute HIV should be given is not clear. Benefits have being shown up to 3 - 4 months after infection, but long-term effects on morbidity and mortality are unknown. Most clinicians would choose to treat within the first 6 months after seroconversion. ${ }^{4}$

Guidelines for initiation of therapy for patients in whom acute HIV-1 infection has been diagnosed are often vague and lack consensus.

The US Department of Health and Human Services (DHHS) guidelines recommend consideration of treatment for patients who received their diagnosis $<6$ months after infection. These guidelines consider treatment to be optional as clinical trials information is limited and benefits and risks of treatment need to be weighed up when considering initiating treatment. ${ }^{24}$

The British HIV Association (BHIVA) guidelines recognise that there are inconsistent study results on treatment in acute HIV. The justification for treating $\mathrm{AHI}$ is to preserve specific anti-HIV immune responses, reduce morbidity associated with high viraemia and CD4+ Tcell depletion and reduce the risk of HIV transmission. These guidelines recommend treatment of $\mathrm{AHI}$ for the relief of symptoms of ARS with neurological involvement, for any AIDS-defining illness or a CD4+ T-cell count persistently $<200$ cells/ml. BHIVA guidelines recommend that there is currently insufficient evidence to support treatment for other indications. ${ }^{25}$

Both the International AIDS Society-USA Panel recommendations and South African HIV Clinicians Society Guidelines do not currently recommend ART for AHI as there is no definitive evidence supporting this therapy. ${ }^{26,27}$

Reasons not to treat patients with $\mathrm{AHI}$ include no proven efficacy of treatment in this period, drug toxicity, and the potential development of drug resistance. Treatment should only be considered in a research trial or in the presence of very severe symptoms after consultation with an expert HIV clinician. ${ }^{27}$

\section{EXPECTED OUTCOMES OF EARLY TREATMENT}

The time taken to achieve viral suppression in AHI may be dependent on a number of host factors. High initial viral loads may prolong the time to viral suppression, while the relatively intact immune system and lower total body viral burden in patients may decrease time to suppression. ${ }^{4}$

Subjects from a multicentre Acute Infection and Early Disease Research Program cohort were enrolled in a study within 6 months of HIV seroconversion and selfselected whether to initiate HAART. CD4+ T-cell counts at 24, 48 and 72 weeks were compared between treated and untreated groups. Initiation of HAART within 2 weeks of seroconversion was associated with viral load and CD4+ T-cell count benefits for 24 weeks after ter- 
mination of HAART. Later initiation of HAART showed less benefit in CD4+ T-cell counts, but viral load benefit lasted till week 72 . The limitations of the study included a lack of random allocation of treatment, variation in duration of treatment, lack of statistical significance of the CD4+ T-cell count and viral load benefits at 72 weeks, the small sample size, and the need for longer follow-up to assess the durability of the apparent benefit. $^{28}$

The application of HAART treatment for AHI is limited by high costs, drug resistance, and drug-related toxicities. New treatment options such as supervised treatment interruption (STI) are being investigated as alternative options. With the STI strategy, HAART is intermittently stopped once viral load has been reduced to a low level, in order to boost natural immunity by brief exposure to the virus. ${ }^{29}$

In a longitudinal open-label study of STI in 14 patients with acute HIV-1 infection, only transient control of viraemia was achieved after drug interruption. A gradual increase in viraemia and decline in CD4+ T-cell counts was observed in most patients, even after a year or more of viral containment. ${ }^{29}$

Data from the SMART (Strategies for Management of Anti-Retroviral Therapy) trial provided evidence that episodic use of ART based on CD4+ T-cell levels was inferior to use of continuous therapy for treatmentexperienced patients and therefore should not be routinely recommended. There was no evidence that interrupting drug exposure was related to fewer adverse events such as myocardial infarction, stroke and renal and liver disease. ${ }^{30}$

The follicular dendritic cell network (FDC) in lymphoid tissues is the major site of HIV storage in the presymptomatic and late stages of disease. In a review of 21 patients from 4 sites, there was no correlation between the duration of infection and accumulation of HIV into the FDC network. The data suggested that a large pool of infectious virus is established soon after infection and that initiation of antiretroviral therapy when symptoms of primary HIV infection are recognised is unlikely to prevent substantial accumulation of virus in the FDC network. Early treatment might, however, maintain immune responses by preserving $\mathrm{CD} 4+\mathrm{T}$ cells and reducing the FDC virus pool. ${ }^{31}$

\section{CONCLUSION}

While it is important on an individual and public health level to identify acute HIV infections, uncertainty still remains regarding the treatment of these identified infections. On a case-by-case basis there may be benefit in treating individuals who present with severe symptoms or persistently low CD4+ T-cell counts to maintain immune system integrity. With regard to the public health benefits, the reduction in transmission needs to be weighed up against the cost and toxicity of widespread treatment.

Other strategies such as vaccines and microbicides also need to be considered in this context in the prevention of transmission and infections.

The author would like to thank Dr Vivian Black for her critical review of the article.

\section{REFERENCES}

1. Lyles RH, Munoz A, Yamashita TE, etal. Natural history of human immunodeficiency virus type 1 viraemia after seroconversion and proximal to AIDS in a large cohort of homosexual men. J Infect Dis 2000; 181: 872-880. http://www.journals. uchicago.edu/doi/pdf/10.1086/315339 (accessed 2 February 2009).

2. Busch MP. Satten GA. Time course of viraemia and antibody seroconversion following human immunodeficiency virus exposure. Am J Med 1997; 102: 117126.

3. Lindback $S$, Thorstensson $R$, Karlsson AC, et al. Diagnosis of primary HIV-1 infection and duration of follow-up after HIV exposure. Karolinska Institute Primary HIV Infection Study Group. AIDS 2000; 14: 2333-2339. http://www. aidsonline.com/pt/re/aids/pdfhandler.00002030-200010200-00014.pdf (accessed 2 February 2009).

4. Kassutto S, Rosenberg ES. Primary HIV type 1 infection. Clin Infect Dis 2004; 38: 1447-1453. http://www.journals.uchicago.edu/doi/pdf/10.1086/420745 (accessed 2 February 2009)

5. Bollinger RC, Brookmeyer RS, Mehendale SM, et al. Risk factors and clinical presentation of acute primary HIV infection in India. JAMA 1997; 278: 20852089. http://jama.ama-assn.org/cgi/reprint/278/23/2085 (accessed 11 February 2009).

6. Stevens $W_{1}$ Akkers $E_{1}$ Myers $M_{1}$ et al. High prevalence of undetected, acute HIV infection in a South African primary care clinic. Abstract, 3rd International AIDS Society (IAS) Conference on HIV Pathogenesis and Treatment, Rio de Janeiro, Brazil, 24-27 July 2005.

7. Pilcher $C D$, Eron JJ Jr, Galvin S, Gay C, Cohen M. Acute HIV revisited: new opportunities for treatment and prevention. J Clin Invest 2004; 113: 937-945. http://www.jci.org/articles/view/21540/pdf (accessed 24 February 2009).

8. Janssen RS, Holtgrave DR, Valdiserri RO, Shephard M, Gayle HD, De Cock KM. The serostatus approach to fighting the HIV epidemic: prevention strategies for infected individuals. Am J Public Health 2001; 91: 1019-1024. http://www.ajph. org/cgi/reprint/91/7/1019 (accessed 24 February 2009).

9. Pilcher $C D$, Eron JJ Jr, Vemazza PL, et al. Sexual transmission during the incubation period of primary HIV infection. JAMA 2001; 286(14): 17131714. http://jama.ama-assn.org/cgi/content/extract/286/14/1713 (accessed 11 February 2009).

10. Geise R, Maenza J, Celum CL. Clinical challenges and diagnostic approaches to recognizing acute human immunodeficiency virus infection. Am J Med 2001; 111 237-238. http://linkinghub.elsevier.com/retrieve/pii/S0002934301008877 (accessed 24 February 2009).

11. Wawer MJ, Gray RH, Sewankambo NK, et al. Rates of HIV-1 transmission per coital act, by stage of HIV-1 infection, in Rakai, Uganda. J Infect Dis 2005; 191: 1403-1409. http://www.journals.uchicago.edu/doi/pdf/10.1086/429411 (accessed 24 February 2009).

12. Novitsky $\mathrm{V}$, Woldegabriel $\mathrm{E}$, Wester $\mathrm{C}$, et al. Identification of primary HIV$1 C$ infection in Botswana. AIDS Care 2008; 20(7): 806-811. http://www. pubmedcentral.nih.gov/articlerender.fcgi?artid=2605733 (accessed 24 February 2009).

13. Vanhems $P$, Hirschel $B$, Phillips $A N$, et al. Incubation time of acute human immunodeficiency virus (HIV) infection and duration of acute HIV infection are independent prognostic factors of progression to AIDS. J Infect Dis 2000; 182: 334-337. http://www.journals.uchicago.edu/doi/pdf/10.1086/315687 (accessed 9 March 2009).

14. Lavreys $L$, Baeten JM, Chohan V, et al. Higher set point plasma viral load and more-severe acute HIV type 1 (HIV-1) illness predict mortality among high-risk HIV-1-infected African women. Clin Infect Dis 2006; 42: 1333-1339. http:// www.journals.uchicago.edu/doi/pdf/10.1086/503258 (accessed 2 February 2009).

15. Bull World Health Organ 4004; 82(6): 462-469. http://www.who.int/bulletin/ en/ (accessed 10 February 2009)

16. Kahn JO, Walker BD. Acute human immunodeficiency virus type 1 infection. NEngl J Med 1998; 339: 33-39. http://content.nejm.org/cgi/content/full/339/1/33 (accessed 24 February 2009).

17. Lavreys $\mathrm{L}$, Thompson $\mathrm{ML}$, Martin $\mathrm{HL}$, et al. Primary human immunodeficiency virus type 1 infection: Clinical manifestations among women in Mombasa, Kenya. Clin Infect Dis 2000; 30: 486-490. http://www.journals.uchicago.edu/ doi/pdf/10.1086/313718 (accessed 2 February 2009).

18. Fiscus $S A$, Pilcher $C D$, Miller WC, et al. Rapid, real-time detection of acute HIV infection in patients in Africa. J Infect Dis 2007; 195: 416-424. http://www. journals.uchicago.edu/doi/pdf/10.1086/510755 (accessed 2 February 2009).

19. Hoen B, Dumon B, Harzic M, et al. Highly active antiretroviral treatment initiated early in the course of symptomatic primary HIV-1 infection: Results of the ANRS 053 trial. J Infect Dis 1999; 180: 1342-1346. http://www.journals.uchicago. edu/doi/pdf/10.1086/315002 (accessed 2 February 2009). 
20. Hicks $C B$, Gay $C$, Ferrari G. Acute HIV infection: the impact of anti-retroviral treatment on cellular immune responses. Clin Exp Immunol 2007; 149: 211-216.S. http://www3.interscience.wiley.com/cgi-bin/fulltext/117996335/PDFSTART (accessed 17 February 2009).

21. Berrey $M M$, Schacker $T$, Collier $A C$, et al. Treatment of primary human immunodeficiency virus type 1 infection with potent antiretroviral therapy reduces frequency of rapid progression to AIDS. J Infect Dis 2001: 183: 14661475. http://www.journals.uchicago.edu/doi/pdf/10.1086/320189 (accessed 2 February 2009).

22. Rosenberg ES, Altfeld M, Poon SH, et al. Immune control of HIV-1 after early treatment of acute infection. Nature 2000; 407: 523-526. http://www. kendallasmith.com/follow/Walker_Nature 928 00.pdf (accessed 17 February 2009).

23. Lacabaratz-Porret C, Urrutia A, Doisne JM, et al. Impact of antiretroviral therapy and changes in virus load on human immunodeficiency virus (HIV)-specific T cell responses in primary HIV infection. J Infect Dis 2003; 187: 748-757. http://www. journals.uchicago.edu/doi/pdf/10.1086/368333 (accessed 17 February 2009).

24. Panel on Antiretroviral Guidelines for Adults and Adolescents. Guidelines for the Use of Antiretroviral Agents in HIV-1-Infected Adults and Adolescents. Department of Health and Human Services. November 3, 2008; 1-139. http:// aidsinfo.nih.gov/contentfiles/AdultandAdolescentGL.pdf (accessed 11 February 2009).

25. Gazzard BG (BHIVA Treatment Guidelines Writing Group). British HIV Association guidelines for the treatment of HIV-1-infected adults with antiretroviral therapy 2008. 2008 British HIV Association. HIV Med 2008; 9: 563-608. http://www. bhiva.org/files/file1030835.pdf (accessed 11 February 2009).

26. Hammer SM, Eron Jل Reiss $P$ et al. Antiretroviral treatment of adult HIV infection: 2008 Recommendations of the International AIDS Society-USA Panel. JAMA 2008; 300(5): 555-570. http://jama.ama-assn.org/cgi/reprint/300/5/555 (accessed 9 March 2009).

27. Maartens G, Venter F, Meintjes G, Cohen K. HIV Clinicians Society Guidelines: Antiretroviral therapy in adults. Southern African Journal of HIV Medicine 2008; Jan: 18-31. http://www.sajhivmed.org.za/index.php/sajhivmed/article/ view/68/34 (accessed 15 February 2009).

28. Hecht FM, Wang $L$, Collier $A$, et al. A multicenter observational study of the potential benefits of initiating combination antiretroviral therapy during acute HIV infection. J Infect Dis 2006: 194: 725-733. http://www.journals.uchicago. edu/doi/pdf/10.1086/506616 (accessed 2 February 2009).

29. Kaufmann $D E$, Lichterfeld $M$, Altfeld $M$, et al. Limited durability of viral contro following treated acute HIV infection. PLoS Med 2004; 1(2): 137-148. http:// medicine.plosjournals.org/archive/1549-1676/1/2/pdf/10.1371_1549-1676 1_2_complete.pdf (accessed 2 February 2009).

30. Jülg $B$, Goebel FD. Treatment interruption in HIV therapy: a SMART strategy? Infection 2006; 34: 186-188. http://www.springerlink.com/content/ 573032284h528150/ (accessed 2 March 2009).

31. Schacker $T$, Little $S$, Connick $E_{1}$ et al. Rapid accumulation of human immunodeficiency virus (HIV) in lymphatic tissue reservoirs during acute and early HIV infection: Implications for timing of antiretroviral therapy. J Infect Dis 2000 181: 354-357. http://www.journals.uchicago.edu/doi/pdf/10.1086/315178 (accessed 2 February 2009).

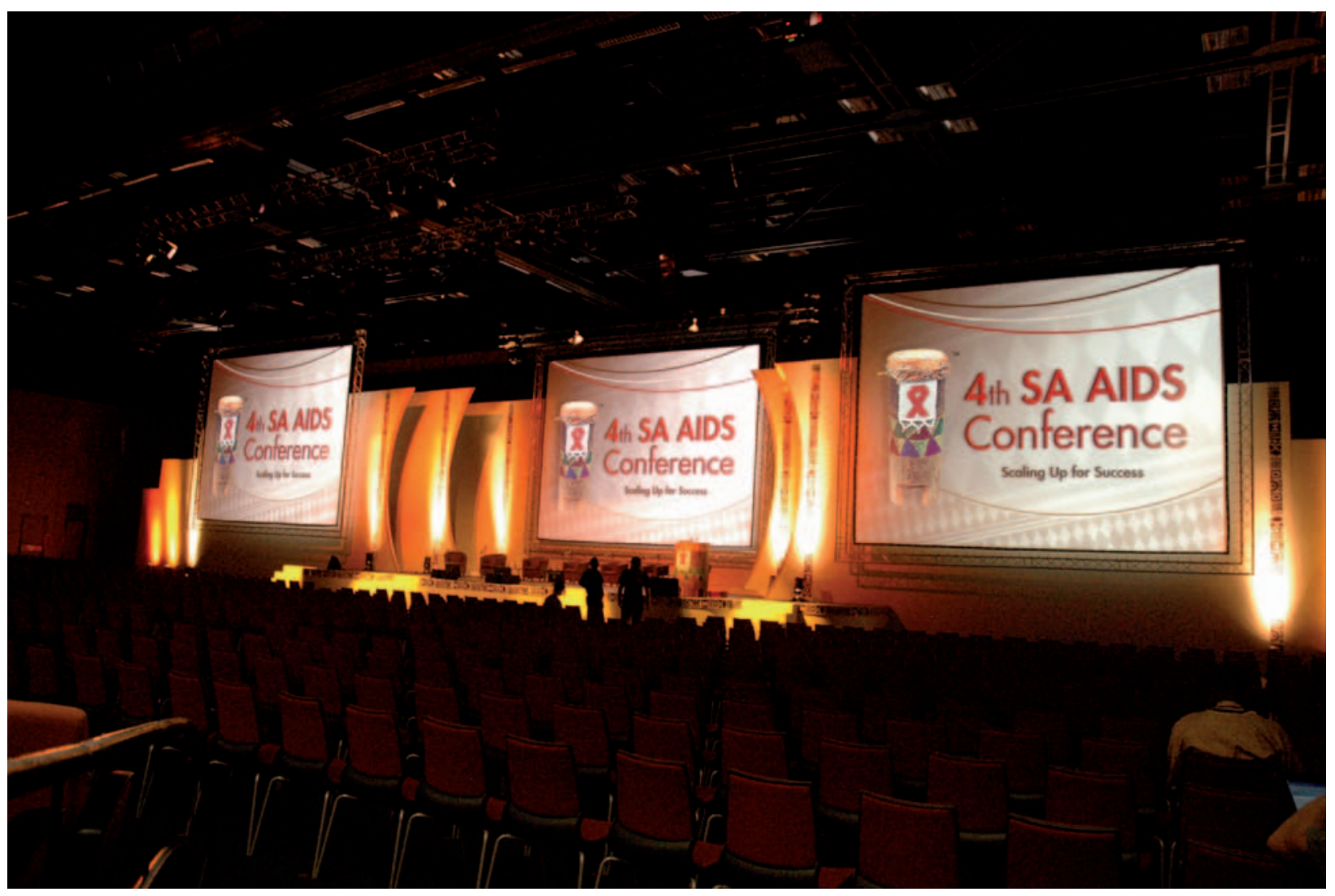

